\title{
LA ECOLOGÍA POLÍTICA EN AMÉRICA LATINA: un campo en construcción*
}

\author{
Enrique Leff ${ }^{* *}$
}

\begin{abstract}
Resumen: El artículo trata de la fundación de la ecología política como campo teórico-practico. A partir del análisis de la desnaturalización de la naturaleza, el estudio plantea el papel de la política cultural, con sus necesarias características de política de la diferencia. Enseguida trata de la cadena conciencia de clase, conciencia ecológica, conciencia de especie, elementos esenciales de la ecología política. El eje de la epistemología política sirve de fundamento al análisis del tema ética y emancipación, que sirve de reflexión conclusiva.
\end{abstract}

Palavras-llave: ecologia política, América Latina.

\section{Emergencia de la ecología política}

La ecología política se encuentra en el momento fundacional de un campo teórico-práctico. Es la construcción de un nuevo territorio del pensamiento crítico y de la acción política. Situar este campo en la geografía del saber no es tan sólo delimitar su espacio, fijar sus fronteras y colocar membranas permeables con disciplinas adyacentes. Más bien implica desbrozar el terreno, dislocar las rocas conceptuales y movilizar el arado discursivo que conforman su suelo original para construir las bases seminales que den identidad y soporte a este nuevo territorio; para pensarlo en su emergencia y en su trascendencia en la configuración de la complejidad ambiental de nuestro tiempo y en la construcción de un futuro sustentable.

\footnotetext{
* Este texto fue presentado en una Reunión del Grupo de Ecología Política de CLACSO, en Panamá, los días 17 - 19 de marzo de 2003 y que fue publicado previamente en Polis, Revista de la Universidad Bolivariana, v. 2, n. 5, p. 125-145.

** Coordenador da Rede de Formação Ambiental para a América Latina e Caribe - PNUMA/ México.
}

Artigo recebido em $1^{\circ}$ ago. 2003; aprovado em 14 set. 2003. 
La ecología política en germen abre una pregunta sobre la mutación más reciente de la condición existencial del hombre. Partiendo de una crítica radical de los fundamentos ontológicos y metafísicos de la epistemología moderna, más allá de una política fundada en la diversidad biológica, en el orden ecológica y en la organización simbólica que dan su identidad a cada cultura, la ecología política viene a interrogar la condición del ser en el vacío de sentido y la falta de referentes generada por el dominio de lo virtual sobre lo real y lo simbólico, de un mundo donde parafraseando a Marshal Berman, todo lo sólido se desvanece en el aire. A la ecología política le conciernen no sólo los conflictos de distribución ecológica, sino el explorar con nueva luz las relaciones de poder que se entretejen entre los mundos de vida de las personas y el mundo globalizado.

Pues si la mirada del mundo desde la hermenéutica y el constructivismo ha superado la visión determinista de la historia y el objetivismo de lo real, si el mundo está abierto al azar y a la incertidumbre, al caos y al descontrol, al diseño y a la simulación, tenemos que preguntarnos, ¿que grado de autonomía tiene la hiperrealidad del mundo sobre-economizado, hiper-tecnologizado y súper-objetivado sobre el ser? ¿en qué sentido se orienta el deseo, la utopía, el proyecto, en la reconfiguración del mundo guiado por intereses individuales, imaginarios sociales y proyectos colectivos? ¿Qué relaciones y estrategias de poder emergen en este nuevo mundo en el que el aleteo de las mariposas puede llegar a conmover, derribar y reconstruir las armaduras de hierro de la civilización moderna y las rígidas estructuras del poder y del conocimiento? ¿Qué significado adquiere la libertad, la identidad, la existencia, la política?

La ecología política construye su campo de estudio y de acción en el encuentro y a contracorriente de diversas disciplinas, pensamientos, éticas, comportamientos y movimientos sociales. Allí colindan, confluyen y se confunden las ramificaciones ambientales y ecológicas de nuevas disciplinas: la economía ecológica, el derecho ambiental, la sociología política, la antropología de las relaciones cultura-naturaleza, la ética política. Podemos afirmar sin embargo 
que no estamos ante un nuevo paradigma de conocimiento o un nuevo paradigma social. Apenas comenzamos a indagar sobre el lugar que le corresponde a un conjunto de exploraciones que no encuentran acomodo dentro de las disciplinas académicas tradicionales. La ecología política es un campo que aún no adquiere nombre propio; por ello se le designa con préstamos metafóricos de conceptos y términos provenientes de otras disciplinas para ir nombrando los conflictos derivados de la distribución desigual y las estrategias de apropiación de los recursos ecológicos, los bienes naturales y los servicios ambientales. Las metáforas de la ecología política se hacen solidarias del límite del sentido de la globalización regida por el valor universal del mercado para catapultear al mundo hacia una reconstrucción de las relaciones de lo real y lo simbólico; de la producción y el saber.

La ecología política emerge en el hinterland de la economía ecológica para analizar los procesos de significación, valorización y apropiación de la naturaleza que no se resuelven ni por la vía de la valoración económica de la naturaleza ni por la asignación de normas ecológicas a la economía; estos conflictos socio-ambientales se plantean en términos de controversias derivadas de formas diversas y muchas veces antagónicas- de significación de la naturaleza, donde los valores políticos y culturales desbordan el campo de la economía política, incluso de una economía política de los recursos naturales y servicios ambientales. De allí surge esa extraña politización de "la ecología".

En la ecología política han anidado así términos que derivan de campos contiguos - la economía ecológica -, como el de distribución ecológica, definido como una categoría para comprender las externalidades ambientales y los movimientos sociales que emergen de "conflictos distributivos"; es decir, para dar cuenta de la carga desigual de los costos ecológicos y sus efectos en las variedades del ambientalismo emergente, incluyendo movimientos de resistencia al neoliberalismo, de compensación por daños ecológicos y de justicia ambiental. La distribución ecológica designa "las asimetrías o desigualdades sociales, espaciales, temporales en el uso que hacen 
los humanos de los recursos y servicios ambientales, comercializados o no, es decir, la disminución de los recursos naturales (incluyendo la pérdida de biodiversidad) y las cargas de la contaminación" (Martínez-Alier, 1997).

La distribución ecológica comprende pues los procesos extraeconómicos (ecológicos y políticos) que vinculan a la economía ecológica con la ecología política, en analogía con el concepto de distribución en economía, que desplaza a la racionalidad económica al campo de la economía política. El conflicto distributivo introduce a la economía política del ambiente las condiciones ecológicas de supervivencia y producción sustentable, así como el conflicto social que emerge de las formas dominantes de apropiación de la naturaleza y la contaminación ambiental. Sin embargo, la distribución ecológica apunta hacia procesos de valoración que rebasan a la racionalidad económica en sus intentos de asignar precios de mercado y costos crematísticos al ambiente, movilizando a actores sociales por intereses materiales y simbólicos (de supervivencia, identidad, autonomía y calidad de vida), más allá de las demandas estrictamente económicas de propiedad de los medios de producción, de empleo, de distribución del ingreso y de desarrollo.

La distribución ecológica se refiere a la repartición desigual de los costos y potenciales ecológicos, de esas "externalidades económicas" que son inconmensurables con los valores del mercado, pero que se asumen como nuevos costos a ser internalizados por la vía de instrumentos económicos, de normas ecológicas o de los movimientos sociales que surgen y se multiplican en respuesta al deterioro del ambiente y la reapropiación de la naturaleza.

En este contexto se ha venido configurando un discurso reivindicativo en torno a la idea de la deuda ecológica, como un imaginario y un concepto estratégico movilizador de una conciencia de resistencia a la globalización del mercado y sus instrumentos de coerción financiera, cuestionando la legitimidad de la deuda económica de los países pobres, buena parte de ellos de América Latina. La deuda ecológica pone al descubierto la parte más grande y hasta ahora sumergida del iceberg del intercambio desigual entre 
países ricos y pobres, es decir, la destrucción de la base de recursos naturales de los países llamados subdesarrollados, cuyo estado de pobreza no es consustancial a una esencia cultural o a su limitación de recursos, sino que resulta de su inserción en una racionalidad económica global que ha sobre-explotado a su naturaleza, degradado a su ambiente y empobrecido a sus pueblos. Sin embargo, esta deuda ecológica resulta inconmensurable, pues no hay tasas de descuento que logren actualizarla ni instrumento que logre medirla. Se trata de un despojo histórico, del pillaje de la naturaleza y subyugación de sus culturas que se enmascara en un mal supuesto efecto de la dotación y uso eficaz y eficiente de sus factores productivos.

Hoy, este pillaje del tercer mundo se proyecta al futuro, a través de los mecanismos de apropiación de la naturaleza por la vía de la etno-bio-prospección y los derechos de propiedad intelectual del "Norte" sobre los derechos de propiedad de las naciones y pueblos del "Sur". La biodiversidad representa su patrimonio de recursos naturales y culturales, con los que han co-evolucionado en la historia, el hábitat en donde se arraigan los significados culturales de su existencia. Estos son intraducibles en valores económicos. Es aquí donde se establece el umbral entre lo que es negociable e intercambiable entre deuda y naturaleza, y lo que impide dirimir el conflicto de distribución ecológica en términos de compensaciones económicas.

El campo de la ecología política se abre en un horizonte que desborda el territorio de la economía ecológica. La ecología política se localiza en los linderos del ambiente que puede ser recodificado e internalizado en el espacio paradigmático de la economía, de la valorización de los recursos naturales y los servicios ambientales. La ecología política se establece en ese espacio que es el del conflicto por la reapropiación de la naturaleza y de la cultura, allí donde la naturaleza y la cultura resisten a la homologación de valores y procesos (simbólicos, ecológicos, epistemológicos, políticos) inconmensurables y a ser absorbidos en términos de valores de mercado. Allí es donde la diversidad cultural adquiere derecho de ciudadanía como una política de la diferencia, de una diferencia radical, en cuanto que lo 
que está allí en juego es más y otra cosa que la distribución equitativa del acceso y los beneficios económicos derivados de la puesta en valor de la naturaleza.

\section{Desnaturalización de la naturaleza}

En el curso de la historia, la naturaleza se fue construyendo como un orden ontológico y una categoría omnicomprensiva de todo lo real. Lo natural se convirtió en un argumento fundamental para legitimar el orden existente, tangible y objetivo. Lo natural era lo que tenía "derecho de ser". En la modernidad, la naturaleza se convirtió en objeto de dominio de las ciencias y de la producción, al tiempo que fue externalizada del sistema económico; se desconoció así el orden complejo y la organización ecosistémica de la naturaleza, en tanto que se fue convirtiendo en objeto de conocimiento y en materia prima del proceso productivo. La naturaleza fue desnaturalizada para convertirla en recurso e insertarla en el flujo unidimensional del valor y la productividad económica. Esta naturalidad del orden de las cosas y del mundo - la naturalidad de la ontología y la epistemología de la naturaleza - fue construyendo una racionalidad contra natura, basada en leyes naturales inexpugnables, ineluctables, inconmovibles.

No es sino hasta los años sesenta y setenta en adelante que la naturaleza se convierte en referente político, no sólo de una política de Estado para la conservación de las bases naturales de sustentabilidad del planeta, sino como objeto de disputa y apropiación social, al tiempo que emergen por fuera de la ciencia diversas corrientes interpretativas, en las que la naturaleza deja de ser un objeto a ser dominado y desmembrado para convertirse en un cuerpo a ser seducido, resignificado, reapropiado. De allí todas las diversas ecosofías, desde la ecología profunda (Naess), el ecosocialismo (O’Connor) y el ecoanarquismo (Bookchin), que nutren a la ecología política. En estas perspectivas, la ecología viene a jugar un papel preponderante en el pensamiento reordenador del mundo. La ecología se convierte en el paradigma que, basado en la comprensión de lo 
real y del conocimiento como un sistema de interrelaciones, orienta el pensamiento y la acción en una vía reconstructiva. De esta manera se establece el campo de una ecología generalizada (Morin) donde se configura toda una serie de teorías y metodologías que iluminan y asechan el campo de la ecología política, desde las teorías de sistemas y los métodos interdisciplinarios, hasta el pensamiento de la complejidad (Floriani, 2003).

Se propuso así un cambio de paradigma epistemológico y societario, del paradigma mecanicista al paradigma ecológico, que si bien contraponía al fraccionamiento de las ciencias la visión holística de un mundo entendido como un sistema de interrelaciones, interdependencias y retroalimentaciones, abriendo el conocimiento hacia la novedad y la emergencia, al caos y a la incertidumbre, la conciencia y la creatividad, no renunció a su pulsión totalizadora y objetivante del mundo. Se generó así un nuevo centralismo teórico, que si empezaba a enfrentar el logocentrismo de las ciencias, no ha penetrado el cerco de poder del pensamiento unidimensional asentado en la ley unitaria y globalizante del mercado. La ecología se fue haciendo política y la política se fue ecologizando, pero a fuerza de abrir la totalidad sistémica fuera de la naturaleza, hacia el orden simbólico y cultural, hacia el terreno de la ética y de la justicia (Borrero, 2002).

Las corrientes dominantes de pensamiento que alimentan la acción ecologista, van complejizando a la naturaleza, pero no logran salir de la visión naturalista que, desde la biosociología hasta los enfoques sistémicos y la ecología generalizada, no han logrado romper el cerco de naturalización del mundo en el que la ley natural objetiva vela las estrategias de poder que han atravesado en la historia las relaciones sociedad-naturaleza.

La ecología política es por ello el terreno de una lucha por la desnaturalización de la naturaleza: de las condiciones "naturales" de existencia, de los desastres "naturales", de la ecologización de las relaciones sociales. No se trata tan sólo de adoptar una perspectiva constructivista de la naturaleza, sino política, donde las relaciones entre seres humanos entre ellos y con la naturaleza se construyen a 
través de relaciones de poder (en el saber, en la producción, en la apropiación de la naturaleza) y los procesos de "normalización" de las ideas, discursos, comportamientos y políticas.

Más allá de los enfoques ecologistas que siguen dominando el pensamiento ambiental, nuevas corrientes constructivistas y fenomenológicas están contribuyendo a la desconstrucción del concepto de naturaleza, resaltando el hecho de que la naturaleza es siempre una naturaleza marcada, significada, geo-grafiada. Dan cuenta de ello los recientes estudios de la nueva antropología ecológica (Descola y Pálsson, 2001) y de la geografía ambiental (Gonçalves, 2001), que muestran que la naturaleza es producto no de una evolución biológica, sino de una coevolución de la naturaleza y las culturas que la han habitado. Son estas "naturalezas orgánicas" (Escobar), las que han entrado en competencia y conflicto con la naturaleza capitalizada y tecnologizada por una cultura globalizada que hoy en día impone su imperio hegemónico y homogeneizante bajo el dominio de la tecnología y el signo unitario del mercado.

La ecología política se establece en el encuentro, confrontación e hibridación de estas racionalidades desemejantes y heterogéneas de relación y apropiación de la naturaleza. Más allá de pensar estas racionalidades como opuestos dialécticos, la ecología política es el campo en el cual se están construyendo - en una historia ambiental cuyos orígenes se remontan a una historia de resistencias anticolonialistas y antiimperialistas - nuevas identidades culturales en torno a la defensa de las naturalezas culturalmente significadas y a estrategias novedosas de "aprovechamiento sustentable de los recursos", de los cuales basta citar la invención de la identidad del seringueiro y de sus reservas extractivistas en la amazonía brasileña, y más recientemente el proceso de las comunidades negras del Pacífico de Colombia. Estas identidades se han configurado a través luchas de resistencia, afirmación y reconstrucción del ser cultural frente a las estrategias de apropiación y transformación de la naturaleza que promueve e impone la globalización económica. Porto Gonçalves ha caracterizado a estos procesos culturales como movimientos de reexistencia. 


\section{Política cultural / Política de la diferencia}

La diferencia es siempre una diferencia radical; está fundada en una raíz cuyo proceso y destino es diversificarse, ramificarse, redificarse. El pensamiento de la diferencia es el proyecto de desconstrucción del pensamiento unitario, aquel que busca acomodar la diversidad a la universalidad y someter lo heterogéneo a la medida de un equivalente universal, cerrar el círculo de las ciencias en una unidad del conocimiento, reducir las variedades ontológicas a sus homologías estructurales y encasillar las ideas dentro de un pensamiento único. La ecología política enraíza el trabajo teórico de desconstrucción del logos en el campo político, donde no basta reconocer la existencia de la diversidad cultural, de los saberes tradicionales, de los derechos indígenas, para luego intentar resolver el conflicto que emana de sus diferentes formas de valorización de la naturaleza por la vía del mercado y sus compensaciones de costos.

Hablamos de ecología política, pero habremos de comprender que la ecología no es política en sí. Las relaciones entre seres vivos y naturaleza, las cadenas tróficas, las territorialidades de las especies, incluso las relaciones de depredación y dominación, no son políticas en ningún sentido. Si la política es llevada al territorio de la ecología es como respuesta al hecho de que la organización ecosistémica de la naturaleza ha sido negada y externalizada del campo de la economía y de las ciencias sociales. Las relaciones de poder emergen y se configuran en el orden simbólico y del deseo del ser humano, en su diferencia radical con los otros seres vivos que son objeto de la ecología.

Desde esta perspectiva, al referirse a las "ecologías de la diferencia", Escobar pone el acento en la noción de "distribución cultural", como los conflictos que emergen de diferentes significados culturales, pues "el poder habita a los significados y los significados son la fuente del poder" (Escobar, 2000, p. 9). Pero si bien el poder se moviliza por medio de estrategias discursivas, la "distribución cultural" no surge del hecho de que los significados sean directamente fuentes de poder, sino de las estrategias discursivas que generan los 
movimientos por la reivindicación de sus valores culturales, es decir, en los procesos de legitimación de los significados culturales como derechos humanos. Pues es por la vía de los derechos (humanos) que los valores culturales entran en el juego y el campo del poder establecido por los "derechos del mercado".

Pero en realidad la noción de distribución cultural puede llegar a ser tan falaz como la de distribución ecológica cuando se le somete a un proceso de homologación y homogeneización. La inconmensurabilidad no sólo se da en la diferencia entre economía, ecología y cultura, sino dentro del propio orden cultural, donde no existen equivalencias entre significaciones diferenciadas. La distribución siempre apela a una materia homogénea: el ingreso, la riqueza, la naturaleza, la cultura, el poder. Pero el ser que funda los derechos es esencialmente heterogéneo, en el sentido de que implica pasar del concepto genérico del ser y del ser ahí heideggeriano, aún herederos de una ontología existencialista esencialista y universal, a pensar la política de la diferencia como derechos del ser cultural, específico y localizado.

La ecología política en América Latina está operando así un proceso similar al que Marx realizó con el idealismo hegeliano, al "poner sobre sus pies" a la filosofía de la posmodernidad (Heidegger, Derrida), al volver al Ser y a la diferencia en la sustancia de una ecología política. La esencial diversidad del orden simbólico y cultural se convierte en la materia de la política de la diferencia.

Pero la diferencia de valores y visiones culturales no se convierte por derecho propio en fuerza política. La legitimación de esa diferencia que le da valor y poder, proviene de una suerte de efectos de saturación de la homogeneización forzada de la vida inducida por el pensamiento metafísico y la racionalidad modernizante. Es de la resistencia del ser al dominio de la homogeneidad hegemónica, de la cosificación objetivante, de la igualdad inequitativa, que surge la diferencia por el encuentro con la otredad, en la confrontación de la racionalidad dominante con lo que le es externo y con aquello que excluye, rompiendo con la identidad 
de la igualdad y la unidad de lo universal. De esa tensión se establece el campo de poder de la ecología política, de la demarcación del pensamiento único y la razón unidimensional, para valorar la diferencia del ser y convertirlo en un campo de fuerzas políticas.

Hoy es posible afirmar que "las luchas por la diferencia cultural, las identidades étnicas y las autonomías locales sobre el territorio y los recursos están contribuyendo a definir la agenda de los conflictos ambientales más allá del campo económico y ecológico", reivindicando las "formas étnicas de alteridad comprometidas con la justicia social y la igualdad en la diferencia" (Escobar, 2000, p. 6, 13). Esta reivindicación no reclama una esencia étnica ni derechos fincados en el principio jurídico y metafísico del individuo, sino en el derecho del ser, que incluye tanto los valores intrínsecos de la naturaleza como los derechos humanos diferenciados culturalmente, incluyendo el derecho a disentir de los sentidos preestablecidos y legitimados por poderes hegemónicos.

La política de la diferencia no sólo implica diferenciar criterios, opiniones y posiciones. También hay que entenderla en el sentido que asigna Derrida (1989) a la diferancia, que no sólo establece la diferencia en el aquí y el ahora, sino que la abre al tiempo, al devenir, al advenimiento de lo impensado y lo inexistente. En este sentido, frente al cierre de la historia en torno al cerco del pensamiento único y del mercado globalizado, la política de la diferencia abre la historia hacia la utopía de la construcción de sociedades sustentables diferenciadas. El derecho a diferir en el tiempo abre el sentido del ser que construye en el tiempo aquello que es potencialmente posible desde lo real y del deseo, "lo que aún no es" (Levinas, 1977).

La ecología política reconoce en el ambientalismo luchas de poder por la distribución de bienes materiales (valores de uso), pero sobre todo de valores-significaciones asignadas a los bienes, necesidades, ideales, deseos y formas de existencia que definen los procesos de adaptación / transformación de los grupos culturales a la naturaleza. No se trata pues de un problema de inconmensurabilidad de bienes-objeto, sino de identidades-valoraciones diferenciadas por 
formas culturales de significación, tanto de la naturaleza como de la existencia misma. Esto está llevando a imaginar y construir estrategias de poder capaces de vincular y fortalecer un frente común de luchas políticas diferenciadas en la vía de la construcción de un mundo diverso guiado por una racionalidad ambiental (hibridación de diversas racionalidades) y una política de la diferencia. De ese otro mundo posible por el que claman las voces del Foro Social Mundial; de otro mundo donde quepan muchos mundos (Sub-comandante Marcos).

Las reivindicaciones por la igualdad en el contexto de los derechos humanos genéricos del hombre, y sus aplicaciones jurídicas a través de los derechos individuales, son incapaces de asumir este principio político de la diferencia que reclama un lugar propio dentro de una cultura de la diversidad, pues como afirma Escobar,

Ya no es el caso de que uno pueda contestar la desposesión y argumentar a favor de la igualdad desde la perspectiva de la inclusión dentro de la cultura y la economía dominantes. De hecho, lo opuesto está sucediendo: la posición de la diferencia y la autonomía está llegando a ser tan válida, o más, en esta contestación. El apelar a las sensibilidades morales de los poderosos ha dejado de ser efectiva [...] Es el momento de ensayar [...] las estrategias de poder de las culturas conectadas en redes y glocalidades, de manera que puedan negociarse concepciones contrastantes de lo bueno y el valor de diferentes formas de vida y para reafirmar el predicamento pendiente de la diferenciaen-la-igualdad. (Escobar, 2000, p. 21).

\section{Conciencia de clase, conciencia ecológica, conciencia de especie}

La política de la diferencia se sitúa en otro plano que el de una ecología política subsumida en el pensamiento ecológico. Pues la significancia de la naturaleza que mueve a los actores sociales en el campo de la ecología política no podría proceder ni fundarse en una conciencia genérica de la especie humana. La "conciencia ecológica" que emana de la narrativa ecologista como una noosfera que emerge desde la organización biológica del cuerpo social humano - esa 
formación discursiva desde la cual la gente habla del amor a la naturaleza, se conmueve por el cuidado del ambiente y promueve el desarrollo sostenible - no es consistente con bases teóricas ni con visiones y proyectos compartidos por la humanidad en su conjunto. Por ello los "tomadores de decisiones" pueden anteponer la conciencia económica a la de la supervivencia humana y del planeta, y negar las evidencias científicas sobre el cambio climático; por ello los principios del desarrollo sostenible (las responsabilidades comunes pero diferenciadas, el consentimiento previo e informado, el pensar globalmente y actuar localmente, o el principio de quien contamina paga) se han convertido en slogans con un limitado efecto en la construcción de una nueva racionalidad ambiental. El movimiento ambientalista es un campo disperso de grupos sociales que antes de solidarizarse por un objetivo común, muchas veces se confrontan, se diferencian y se dispersan tanto por el fraccionamiento de sus reivindicaciones como por la comprensión y uso de conceptos que definen sus estrategias políticas.

Para que hubiera una conciencia de especie sería necesario que la humanidad en su conjunto compartiera la vivencia de una catástrofe común o de un destino compartido por todo el género humano en términos equivalentes, como aquella que llevó el silogismo aristotélico sobre la mortalidad del hombre a una conciencia de sí de la humanidad cuando la generalización de la peste convirtió el simbolismo del silogismo en experiencia vivida, transformando la máxima del enunciado en producción de sentido de un imaginario colectivo (o la que fundó la cultura humana en la prohibición del incesto y de la cual el simbolismo del complejo de Edipo vino solamente a convertir en sentido trágico y manifestación literaria una "ley cultural" vivida, que no fue instaurada ni por Sófocles ni por Freud). Pues como ha afirmado Lacan (1974/75), del enunciado de Aristóteles "todos los hombres son mortales" no se desprende el sentido que sólo anidó en la conciencia una vez que la peste se propagó por Tebas, convirtiéndola en algo "imaginable" y no sólo una pura forma simbólica, una vez que toda la sociedad se sintió concernida por la amenaza de una muerte real.

En la sociedad del riesgo y la inseguridad en que vivimos podemos afirmar que el imaginario del terror está más concentrado 
en la realidad de la guerra y la violencia generalizada que en el peligro inminente de un colapso ecológico. Pareciera que el holocausto y los genocidios a lo largo de la historia humana no hubieran sido capaces de anteponer una ética de la vida a los intereses del poder; menos aún una conciencia que responda efectivamente al riesgo ecológico o con un imaginario colectivo que reconduzca sus acciones hacia la construcción de sociedades sustentables. La crisis ambiental que se cierne sobre el mundo aún se percibe como una premonición catastrofista de una naturaleza que se presume cada vez más controlada, más que como un riesgo ecológico real para toda la humanidad. La amenaza que se ha establecido en el imaginario colectivo y que mantiene pasmado al mundo actual es la del terrorismo que se manifiesta en un miedo generalizado a la guerra desenfrenada, al holocausto humano, al derrumbe de reglas básicas de convivencia y de una ética de y para la vida, más que como la conciencia de la revancha de una naturaleza sometida y sobreexplotada.

Ciertamente prácticamente todo el mundo tiene hoy conciencia de problemas ecológicos que afectan su calidad de vida; pero estos se encuentran fragmentados y segmentados según su especificidad local. Estos generan una variedad de ambientalismos (Guha y Martínez Alier, 1997), pero no todas las formas y grados de conciencia generan movimientos sociales. Más bien prevalece lo contrario, y los problemas más generales, como el calentamiento global, son percibidos desde visiones y concepciones muy diferentes, desde quienes ven allí la fatalidad de catástrofes naturales hasta quienes lo entienden como la manifestación de la ley límite de la entropía y el efecto de la racionalidad económica. El ambientalismo es pues un kaleidoscopio de teorías, ideologías, estrategias y acciones no unificadas por una conciencia de especie, salvo por el hecho de que el discurso ecológico ha empezado a penetrar todas las lenguas y todos los lenguajes, todos los idearios y todos los imaginarios.

La ley límite de la entropía que sustentaría desde la ciencia tales previsiones y los desastres "naturales" que se han desencadenado y proliferado en los últimos años parecen aún disolver su evidencia en los cálculos de probabilidades, en la incertidumbre vaga de los acontecimientos, en el corto horizonte de las evaluaciones y la 
multiplicidad de criterios en los que se elaboran sus indicadores. Lo que prevalece es una dispersión de visiones y previsiones sobre la existencia humana y su relación con la naturaleza, en la que se borran las fronteras de las conciencias de clase, pero no por ello las diferencias de conciencias alimentadas por intereses y valores diferenciados, en los que el principio de diversidad cultural está abriendo un nuevo mosaico de posicionamientos que impide la visión unitaria para salvar al planeta, a la biodiversidad y a la especie humana. Cada visión se está convirtiendo en nuevos derechos que están resquebrajando el marco jurídico prevaleciente, construido en torno al principio de la individualidad y del derecho privado, de la misma forma que esos pilares de la racionalidad económica se colapsan frente a lo real de la naturaleza y los sentidos de la cultura.

Esta recomposición del mundo por la vía de la diferenciación del ser y del sentido rompe el esquema imaginario de la interdisciplinariedad, e incluso de un "diálogo de saberes" entendido como la concertación de intereses diferenciados a través de una racionalidad comunicativa (Habermas). La conciencia de la crisis ambiental se funda en la relación del ser con el límite, en el enfrentamiento del todo objetivado del ente con la nada que alimenta el advenimiento del ser, en la interconexión de lo real, lo imaginario y lo simbólico que oblitera al sujeto, que abre el agujero de donde emerge la existencia humana, el ser y su relación con el saber. El sujeto de la ecología política no es el hombre construido por la antropología ni el ser-ahí genérico de la fenomenología, sino el ser propio que ocupa un lugar en el mundo, que construye su mundo de vida como "producción de existencia" (Lacan, 1974/75): la nada, la falta en ser y la pulsión de vida que van impulsando y anudando el posible saber en la producción de la existencia, forjando esa relación del ser y el saber, del ser con lo sido y lo que aún no es, de una utopía que está más allá de toda trascendencia prescrita en una evolución ecológica, sea esta orgánica o de una dialéctica ecologizada de la naturaleza (Bookchin, 1990).

La conciencia ecológica se inscribe así en una política de la diferencia referida a los derechos del ser y a la invención de nuevas identidades atravesadas y constituidas en y por relaciones de poder. 


\section{Ecología política / Epistemología política}

La ecología política es la política de la reapropiación de la naturaleza. Pero como toda política, no es meramente una estrategia práctica; su práctica no sólo está mediada por procesos discursivos y por aplicaciones del conocimiento, sino que es esencialmente una lucha que se da en la producción y apropiación de los conceptos. No sólo porque el ambientalismo crítico combate las ideologías que fundan la racionalidad de la modernidad insustentable (Leis, 2001), sino porque la eficacia de una estrategia de reconstrucción social implica la desconstrucción de los conceptos teóricos e ideológicos que han soportado y legitimado las acciones y procesos generadores de los conflictos ambientales. La orientación de las acciones hacia la construcción de sociedades sustentables se da en un campo de luchas teóricas y de politización de conceptos. Así, los conceptos de biodiversidad, territorio, autonomía, autogestión, están reconfigurando sus significados en el campo conflictivo de las estrategias de reapropiación de la naturaleza.

La política de la diferencia se abre a una proliferación de sentidos existenciales y civilizatorios que son la materia de una epistemología política que desborda al proyecto interdisciplinario en su voluntad de integración y complementariedad de conocimientos (las teorías de sistemas), reconociendo las estrategias de poder que se juegan en el campo del saber y reconduciendo el conflicto ambiental hacia un encuentro y diálogo de saberes. Ello implica una radical revisión del conocimiento, de la relación entre lo real, lo simbólico y lo imaginario, donde la solución no se orienta a copiar a la naturaleza, a subsumirse profundamente en la ecología, o a generalizar la ecología como modelo de pensamiento y comportamiento, sino a situarse políticamente en lo imaginario de las representaciones de la naturaleza para desentrañar sus estrategias de poder (del discurso del desarrollo sostenible). Se trata no sólo de una hermenéutica de los diferentes sentidos asignados a la naturaleza, sino de saber que toda naturaleza es captada desde un lenguaje, desde relaciones simbólicas que entrañan visiones, sentimientos, razones, sentidos e intereses que se debaten en la arena política. Porque el poder que habita al cuerpo humano está hecho de lenguaje. 
Es dentro de esta epistemología política que los conceptos de territorio-región funcionan como lugares-soporte para la reconstrucción de identidades enraizadas en prácticas culturales y racionalidades productivas sustentables, como hoy lo construyen las comunidades negras del Pacífico colombiano. En este escenario,

El territorio es visto como un espacio multidimensional fundamental para la creación y recreación de las prácticas ecológicas, económicas y culturales de las comunidades [...] Puede decirse que en esta articulación entre identidad cultural y apropiación de un territorio subyace la ecología política del movimiento social de comunidades negras. La demarcación de territorios colectivos ha llevado a los activistas a desarrollar una concepción del territorio que enfatiza articulaciones entre los patrones de asentamiento, los usos del espacio y las prácticas de usos-significados de los recursos. (Escobar, 1999, p. 260)

Una ecología política bien situada se sustenta en una teoría correcta de las relaciones sociedad-naturaleza, o en la desconstrucción de la noción ideológico-científica-discursiva de la naturaleza, capaz de articular la sustancia ontológica de lo real del orden biofísico, con el orden simbólico que la significa, que la convierte en referente de una cosmovisión, de una teoría, de un discurso sobre el desarrollo sustentable. La ecología política remite directamente al debate sobre monismo/dualismo en el que hoy se desgarra la teoría de la reconstrucción / reintegración de lo natural y lo social, de la ecología y la cultura, de lo material y lo simbólico. Es allí donde se ha desbarrancado el pensamiento ambiental, bloqueado por efecto del maniqueísmo teórico y la dicotomía extrema entre el naturalismo de las ciencias físico-biológico-matemáticas y el antropomorfismo de las ciencias de la cultura; unas llevadas al polo positivo del positivismo lógico y empirista; el otro al relativismo del constructivismo y de la hermenéutica. En el naufragio del pensamiento ante su polarización extrema, pensadores y científicos se han agarrado de la tabla de salvación que les ha ofrecido la ecología como ciencia por excelencia e las interrelaciones de los seres vivos con sus entorno, llevando a una ecología generalizada que no logra desprenderse e esa voluntad de totalización del mundo, ahora guiada por el objetivo de construir un pensamiento de la complejidad (Morin, 1993). Surgen de allí todos 
los intentos por reconciliar a esos entes no dialogantes (mente-cuerpo; naturaleza-cultura; razón-sentimiento), más allá de una dialéctica de contrarios, unificados por un creacionismo evolucionista, de donde habría de emerger la conciencia ecológica para reconciliar y saldar las deudas de una racionalidad anti-ecológica. Este pensamiento complejo en búsqueda de un paradigma monista fundado en la ecología no ofrece bases sólidas a una ecología política capaz de guiar las acciones hacia una sustentabilidad fundada en una política de la diferencia.

La otra falla del pensamiento epistemológico reciente ha sido querer reunificar la naturaleza y la cultura sobre la base de una perspectiva fenomenológica a partir de la constatación de que las cosmovisiones de las sociedades "tradicionales" no reconocen una distinción entre lo humano, lo natural y lo sobrenatural. Empero estas "matrices de racionalidad" no constituyen "epistemologías" conmensurables, equiparables con la epistemología de nuestra civilización “occidental". De manera que si bien podemos inspirarnos en las gnoseologías de las sociedades tradicionales para una política de la diferencia basada en el derecho de sus saberes, el campo general de la epistemología que anima y legitima la política de la globalización económico-ecológica debe desconstruirse desde el cuerpo mismo de sus fundamentos.

La posmodernidad está marcada por el fin de los universalismos y los esencialismos; por la emergencia de entes híbridos hechos de organismo, símbolos y tecnología (Haraway); por la imbricación de lo tradicional y lo moderno. Pero es necesario diferenciar este reenlazamiento de lo natural, lo cultural y lo tecnológico del mundo actual de la complejidad, del mundo de vida de los primitivos que desconocen la separación entre cuerpo y alma, vida y muerte, naturaleza y cultura. Esta continuidad y fluidez del mundo primitivo se da en un registro diferente a la relación entre lo real, lo simbólico y lo imaginario en la cultura moderna.

El problema a resolver por la ecología política no es sólo el dejar atrás el esencialismo de la ontología occidental, sino el principio de universalidad de la ciencia moderna. Pues la ciencia ha generado, 
junto con sus universales a priori, al hombre genérico que se convirtió en el principio de discriminación de los hombres diferentes. De esta manera, los derechos humanos norman y unifican al tiempo que segregan y discriminan. Por ello, la ecología política debe salir a la desconstrucción de todos los conceptos universales y genéricos: el hombre, la naturaleza, la cultura, etc., pero no para pluralizarlos como "hombres", "naturalezas" y "culturas" (con sus propias "ontologías" y "epistemologías"), sino para construir los conceptos de su diferencia. Así pues, el ecofeminismo no debe tan sólo diagnosticar los lugares asignados a la mujer en la economía, la política, la familia. Su diferencia sustantiva no radica en el lugar (diferente, subyugado) que le asigna la cultura jerárquica falocéntrica, sino en decir su diferencia con un lenguaje propio, que no es sólo el agregado de sensibilidad a la supuesta racionalidad inconmovible del machismo. La ecología política habrá de edificarse y convivir en una babel de lenguajes diferenciados, que se comunican e interpretan pero que no se traducen en un lenguaje común unificado.

Esta epistemología política trasciende el juego de interrelaciones e interdependencias del pensamiento complejo fundado en una ecología generalizada (Morin) y en un naturalismo dialéctico (Bookchin), ya que está situada más allá de todo naturalismo. Esta emerge desde ese orden que inaugura la palabra, el orden simbólico y la producción de sentido. En esta perspectiva, la ecología política no emerge del orden ecológico preestablecido, ni de una ciencia que haría valer una conciencia-verdad capaz de vencer los intereses antiecológicos y antidemocráticos, sino en un nuevo espacio donde el destino de la naturaleza se juega en un proceso de creación de sentidos-verdades y en sus respectivas estrategias de poder. Ese reanudamiento entre lo real, lo simbólico y lo imaginario es lo que pone en juego las leyes de la naturaleza (entropía como ley límite de lo real) con lo simbólico de su teoría y con la discursividad del desarrollo sostenible. Esta cuestión epistemológica no se dirime en el campo del conocimiento, sino en el de la política que hace intervenir otros símbolos, otros imaginarios y otros reales, en el sentido de que la naturaleza (la biodiversidad) no son entidades objetivas desde el momento en que la naturaleza se construye desde el efecto de poder 
de los procesos imaginarios y simbólicos que la transforman en geopolítica del desarrollo sostenible.

\section{Ética y emancipación}

La ecología política busca su identidad teórica y política en un mundo en mutación, en el que las concepciones y conceptos que hasta ahora orientaron la inteligibilidad del mundo y la acción práctica, parecen desvanecerse del campo del lenguaje significativo. Sin embargo, el pensamiento dominante se resiste a abandonar el diccionario de las prácticas discursivas que envuelven a la ecología política (como a todos los viejos y nuevos discursos que acompañan la desconstrucción del mundo) a pesar de que han perdido todo peso explicativo y resuenan como la nostalgia de un mundo para siempre pasado, para siempre perdido: el del pensamiento dialéctico, el de la universalidad y unidad de las ciencias, el de la esencia de las cosas y la trascendencia de los hechos. Y sin embargo algo nuevo puja por salir y manifestarse en este mundo de incertidumbres, de caos y confusión, de sombras y penumbras, donde a través de los resquicios y resquebrajamientos de la racionalidad monolítica del pensamiento totalitario, se asoman las primeras luces de la complejidad ambiental. Llamemos a ese algo inconformidad, lucidez mínima, necesidad de comprensión y de emancipación. Mientras los juegos de lenguaje son infinitos para seguir imaginando este mundo de ficción y virtualidad, también lo son para avizorar futuros posibles, para construir utopías, para reconducir la vida. Y el pensamiento que ya nunca será único ni servirá como instrumento de poder, busca comprender, enlazar su poder simbólico y sus imaginarios para reconducir lo real. Y si este proceso no deberá sucumbir al poder perverso y anónimo de la hiperrealidad y la simulación guiadas por el poder o por la aleatoriedad de las cosas, un principio básico seguirá sosteniendo la existencia en la razón, y es la de la consistencia del pensamiento, consistencia que nunca será total en un mundo que nunca será totalmente conocido y controlado por el pensamiento. Que nunca más será regido por razones de fuerza mayor.

La crisis ambiental marca el límite del logocentrismo y la voluntad de unidad y universalidad de la ciencia, del pensamiento 
único y unidimensional, de la racionalidad entre fines y medios, de la productividad económica y la eficiencia tecnológica, del equivalente universal como medida de todas las cosas, que bajo el signo monetario y la lógica del mercado han recodificado al mundo y los mundos de vida en términos de valores de mercado intercambiables y transables. De allí que la emancipación se plantee no sólo como un antiesencialismo, sino como de-sujeción de la sobreeconomización del mundo. Lo anterior implica resignificar los principios liberadores de la libertad, la igualdad y la fraternidad como principios de una moral política que terminó siendo cooptada por el liberalismo económico y político - por la ecualización y privatización de los derechos individuales, de fraternidades disueltas por el interés y la razón de fuerza mayor -, para renombrarlos en la perspectiva de la desujeción y la emancipación, de la equidad en la diversidad, de la solidaridad entre seres humanos con culturas, visiones e intereses colectivos, pero diferenciados.

La ecología política es una política de la diferencia, de la diversificación de sentidos; más allá de una política para la conservación de la biodiversidad que sería recodificada y revalorizada como un universal ético o por el equivalente universal del mercado, es una transmutación de la lógica unitaria hacia la diversificación de proyectos de sustentabilidad y ecodesarrollo. Esta política es una revolución que abre los sentidos civilizatorios, no por ser una revolución de la naturaleza ni del conocimiento científico-tecnológico (biotecnológica), sino por ser una revolución del orden simbólico, lo que implica poner el espíritu desconstruccionista del pensamiento posmoderno al servicio de una política de la diferencia, proponer la "imaginación abolicionista" como principio de libertad y de sustentabilidad:

La agenda abolicionista propone comunidades autogestionarias establecidas de acuerdo al ideal de organización espontánea: los vínculos personales, las relaciones de trabajo creativo, los grupos de afinidad, los cabildos comunales y vecinales; fundadas en el respeto y la soberanía de la persona humana, la responsabilidad ambiental y el ejercicio de la democracia directa "cara a cara" para la toma de decisiones en asuntos de interés colectivo. Esta agenda apuntaba a 
cambiar nuestro rumbo hacia una civilización de la diversidad, una ética de la frugalidad y una cultura de baja entropía, reinventando valores, desatando los nudos del espíritu, sorteando la homogeneidad cultural con la fuerza de un planeta de pueblos, aldeas y ciudades diversos. (Borrero, 2002, p. 136)

El discurso de la ecología política no es el discurso lineal que hace referencia a los "hechos", sino aquél de la poesía y la textura conceptual que al tiempo que enlaza la materia, los símbolos y los actos que constituyen su territorio y su autonomía de su campo teóricopolítico, también llevan en ciernes la desconstrucción de los discursos de los paradigmas y las políticas establecidas, para abrirse hacia el proceso de construcción de una nueva racionalidad a partir de los potenciales de la naturaleza y los sentidos de la cultura, de la actualización de identidades y la posibilidad de lo que "aún no es".

La ecología política no solamente explora y actúa en el campo del poder que se establece dentro del conflicto de intereses por la apropiación de la naturaleza; a su vez hace necesario repensar la política desde una nueva visión de las relaciones de la naturaleza, la cultura y la tecnología. Más que actuar en el espacio de una complejidad ambiental emergente, se inscribe en la búsqueda de un nuevo proyecto libertario para abolir toda relación jerárquica y toda forma de dominación. Más allá de estudiar los conflictos ambientales, está constituida por un conjunto de movimientos sociales y prácticas políticas que se manifiestan dentro de un proceso de emancipación. La ecología política se funda en un nuevo pensamiento y en una nueva ética: una ética política para renovar el sentido de la vida (Leff, 2002; PNUMA 2002).

Así, dentro de la imaginación abolicionista y el pensamiento libertario que inspira a la ecología política, la disolución del poder de una minoría privilegiada para sojuzgar a las mayorías excluidas es tarea prioritaria para la ecología política. La ecología política de América Latina deberá ser un árbol cultivado por nuestras vidas y las de tantos movimientos sociales que se cobijan bajo su follaje; un árbol con ramas que enlacen diversas lenguas, una Babel donde nos comprendamos desde nuestras diferencias, donde cada vez que alcemos el brazo para alcanzar sus frutos degustemos el sabor de cada 
terruño de nuestra geografía, de cada cosecha de nuestra historia y cada producto de nuestra invención. De ser así, tal vez no tardemos mucho en darle nombre propio a su savia, como esos seringueiros que se inventaron como seres en este mundo bajo el nombre de ese árbol del que con su ingenio extrajeron el alimento de sus cuerpos y vida de su cultura.

Resumo: O artigo aborda a fundação da ecologia política como campo teórico-prático. A partir da análise da desnaturalização da natureza, o estudo enfoca o papel da política cultural, com suas necessárias características de política da diferença. Em seguida, trata da cadeia consciência de classe, consciência ecológica, consciência de espécie, elementos essenciais da ecologia política. O eixo da epistemologia política fundamenta a análise do tema ética e emancipação, que serve de reflexão conclusiva.

Palavras-chave: ecologia política, América Latina.

Abstract: The article faces the foundation of political ecology as a theoretical-practical field. Starting with the analysis of the denaturalization of nature, it focuses the role of the culture policy, as a policy of difference. After this, it treats the chain class consciousness, ecological consciousness, species consciousness, as necessary elements of political ecology. The axis of political epistemology serves as a reference to the analysis of ethics and emancipation, a subject taken as a conclusive consideration.

Key-words: political ecology, Latin America.

\section{Referências bibliográfícas}

BAUDRILLARD, J. L'echange symbolique et la mort. Paris: Gallimard, 1986.

BOOKCHIN, M. The Philosophy of Social Ecology: essays on dialectical Naturalism. Montreal: Black Rose Books, 1990.

BORRERO, J. M. La imaginación abolicionista: ensayos de ecología política. Cali: PNUMA/CELA/Hivos, 2002.

DERRIDA, J. Márgenes de la Filosofía. Madrid: Cátedra, 1989.

DESCOLA, P.; PÁLSSON, G. (Eds.). Naturaleza y sociedad: perspectivas antropológicas. México: Siglo XXI, 2001. 
ESCOBAR, A. El final del salvaje: naturaleza, cultura y política en la antropología contemporánea. Bogotá: CEREC/ICAN, 1999.

. An Ecology of difference: equality and conflict in a glocalized world. 2000. Mimeogr.

FLORIANI, D. Conhecimento, meio ambiente e globalização. Curitiba, 2003. Mimeogr.

GONÇALVES, C. W. P. Geo-grafías: movimientos sociales, nuevas territorialidades y sustentabilidad. México: Siglo XXI, 2001.

GUHA, R.; MARTÍNEZ ALIER, J. Varieties of environmentalism: essays North and South. Londres: Earthscan, 1977.

LACAN, J. Seminario RSI (Réel, Symbolique, Imaginaire). 1974-75. Mimeogr.

LEFF, E. Saber ambiental: racionalidad, sustentabilidad, complejidad, poder. México: Siglo XXI, 1998/2002.

Epistemología ambiental. São Paulo: Cortez, 2001.

LEFF, E. (Ed.). Ética, vida, sustentabilidad. México: PNUMA, 2002.

LEIS, H. La modernidad insustentable: las críticas del Ambientalismo a la sociedad contemporánea. Montevideo: PNUMA/Nordan, 2001.

LEVINAS, E. Totalidad e infinito. Salamanca: Ediciones Sígueme, 1977.

MARTÍNEZ ALIER, J. Conflictos de distribución ecológica. Revista Andina, v. 29, n. 1, p. 41-66, 1997.

MORIN, E. Introducción al pensamiento de la complejidad. Barcelona: GEDISA, 1993.

NAESS, A.; ROTHENBERG, D. Ecology, community and lifestyle. Cambridge, Gran Bretaña: University Press, 1989.

PNUMA. Manifiesto por la vida: por una Ética de la sustentabilidad. 2002. Disponível em: <www.rolac.unep.mx>

VATTIMO. Las aventuras de la diferencia. 3. ed. Barcelona: Península, 1998. 